versely as the radius if the density is constant, the pressure will balance the pull on a spherical absorbing particle of the density of the earth if its diameter is about a hundredthousandth of an inch. The possible effects of radiationpressure may be illustrated without going to such fineness as this. In the case of a particle of the density of the earth, and a thousandth of an inch in diameter, going round the sun at the earth's distance, there are two effects due to the sun's radiation. In the first place, the radiation-push is $x / 100$ of the gravitation-pull, and the result is equivalent to a diminution in the sun's mass. In the second place, the radiation absorbed by the particle and given out again on all sides is crushed up in front as the particle moves forward and is opened out behind. There is thus a slightly greater pressure on the advancing hemisphere than on the receding one, and this appears as a small resisting force in the direction of motion. Through this the particle tends to move in a decreasing orbit, spiralling in towards the sun. As there is good reason to believe that some comets, at least, are composed of clouds of dust, there is hope that some of their eccentricities may be explained by the existence of radiation pressure. If the particles of a dust cloud circling round the sun are of different sizes or densities, the radiation accelerations on them will differ. The larger particles will be less affected than the smaller, will travel faster round a given orbit, and will draw more slowly in towards the sun. Thus a comet of particles of mixed sizes will gradually be degraded into a diffused trail lengthening and broadening, the finer dust on the inner and the coarser on the outer edge. If a planet, while still radiating much energy on its own account, captures and attaches to itself, as a satellite, a cometary cloud of dust in which there are several different grades, with gaps in the scale of size, it may be possible that in course of time the radiation-pressure effects will form the different grades into different rings surrounding the planet. Such may possibly be the origin of the rings of Saturn.

\section{GEOGRAPHICAL RESULTS OF THE TIBET MISSION.}

THE paper read by Sir Frank Younghusband at the Royal Geographical Society on Monday, February 13, was one of the most interesting and instructive that the fellows of that society have been privileged to listen to for many years. It afforded a striking exemplification of the advantages of a due coordination of geographical facts and their combination, by a master-hand, into a well-arranged whole. The country traversed by the Tibet mission was by no means a terra incognita to the geographer, for its main features had long been known through the labours of the zealous native explorers of the Survey of India. But it is none the less true that Sir Frank Younghusband's admirable descriptions of the conditions of nature and man in that romantic region enabled his audience to realise those conditions in a way that was never before possible, and brushed away many false ideas which had been previously entertained. The speaker was also able to touch briefly upon some of the results obtained by the scientific experts who accompanied the mission, as well as by the survey party under Captains Rawling and Ryder, which in the late autumn did excellent work along the whole course of the Upper Brahmaputra, proving definitely that no peaks higher than Everest exist on this flank of the Himalayas.

In regard to the general nature of the country traversed, Sir F. Younghusband was able to correct the current idea that the whole of Tibet is more or less barren and worthless. This may be true for northern Tibet, the part traversed by recent European explorers, but not for the southern third, which is dotted over with thriving villages and well-built residences. The valleys in which Lhasa, Gyantse, and Shigatse are situated, as well as that of the Brahmaputra, are neither barren plateaux nor narrow, V-shaped gorges, but flat valleys covered with good soil, well irrigated, and richly cultivated. The passage to Tibet, as made by the Kongra-lama Pass, involves, however, a sudden change from the deep-cut valleys and luxuriant vegetation of Sikkim to wide plains on which not a tree is to be seen, while if, in some secluded nook, a plant a foot high is met NO. I 842 , VOL. 7 I] with it is a curiosity. The summer climate of Khambajong was described as charming, while the unrivalled panorama of the Himalayas, at the very culminating point of their grandeur, is a full compensation for anything that may be otherwise lacking. Sir Frank Younghusband's eloquent descriptions of the snowy range as seen from the north, with the ever-varying atmospheric effects, are of special interest as the first ever given by a European capable of appreciating adequately the glories of the prospect.

The discovery by Mr. Hayden, of the Indian Geological Survey, of a bed of fossil oysters, permitted an accurate determination of the age of the hills in this part of Tibet, showing them to be geologically quite recent, though somewhat older than the main axis of the Himalayan range. The Chumbi Valley, through which the final advance was made, is less wide and open than the valleys in Tibet proper, of which, in fact, it is not considered a part. The passage hence into Tibet, made during the height of winter by the Tang-la Pass, 15,200 feet high, involved much suffering from the effects of the great cold ( $\mathrm{r} 8^{\circ}$ below zero Fahr.) combined with the rarity of the air. The subsequent march over the elevated plateau was made in the teeth of bitter winds and blinding blizzards, which continued through January, February, and March. But on arrival at Gyantse (April II) the pirring cold was left behind. Willow and poplar trees were bursting into foliage, and the banks of the river were covered with masses of iris-plants, which later on became sheets of purple. On July 14, the day of the start for Lhasa, heavy rain destroyed the delusion that Tibet is a rainless country. Frequent rain was experienced until September, and the size of the rivers showed that this part of Tibet receives - probably up the Brahmaputra Valley-a quite considerable rainfall. Finally, in a lovely vallev covered with trees, rich with cultivation, and watered by a river as broad as the Thames at Westminster, the mysterious city which no living European had seen before was at last reached, hidden away by range after range of snowy mountains. It proved anything but a dreamland city, and its streets were horribly muddy, but the grand lama's palace was an imposing, massive structure. Even the leading men were of low mental calibre, having much of the nature of children. The $\mathrm{Ti}$ Rimpochi-the leading lama-though benevolent and genial, had few intellectual attainments, and was firmly convinced that the earth was triangular; while the religion of the Tibetans was described as the most degraded form of Buddhism in existence.

\section{THE LONDON CONFERENCE ON SCHOOL HYGIENE.}

THE conference on school hygiene, organised by the Royal Sanitary Institute, met on February 8,9 , and 1o at the University of London. Sir Arthur Rücker, who was installed as president of the conference, delivered an address in which he insisted that the elements of education should include some knowledge of the dangers by which mankind is surrounded and of the means to keep them at bay, and that those to whom young lives are entrusted should learn the main outlines of hygiene.

The ignorance of household management and of the principles of hygiene among the poor is responsible in no small measure for their high preventable mortality, their inferior physique, their intemperance and their poverty. How possible it is to better the conditions of modern life, and thus to improve the health, happiness, and physical powers of the people, and thereby their mental vigour and industrial efficiency, is generally recognised, and to this end a suitable hygienic education, moral and material, of the future parents seems essential. Not only have 15,000 medical men and the Commissions on Physical Degeneration recommended that such teaching should be made compulsory, but the English Board of Education and the Scotch Education Department have accepted that recommendation. It is important that from the earliest years of school life children should be taught by example as well as precept the elements of healthy living. The knowledge that may be procured subsequent to that age is often gained at the price of a needlessly costly personal experience. The object, then, of school hygiene is to secure for 
the physical life its maximum possibility of sound health, and to develop the mental life side by side with this. The need of bodily health as the foundation of sound mental work is largely recognised at the present day, and we must not rest content until in the homes as well as in the schools there is sound knowledge of what may be done to give the proper environment for healthy life and work.

At the conference considerable prominence was given to the subject of the physical development and physical inspection of the scholar. Fresh air, good light, wholesome food. and abundant sleep are essentials of development. These should form, as it were, the compulsory subjects in childhood. The co-relation between the healthy mind and the healthy body is disputed by no one, and yet it is necessary still to pleac against the unimportant position which is given to physical education in the curriculum of a large majority of schools, particularly in those for girls. The responsibility of the education authority may be said to be of a dual nature, viz. the responsibility not to injure the child's health during school life either by bad building or furniture, by the discipline or curriculum of the school, or by preventable risks of infection, and the responsibility to take the consequence of its own defective training of the future parent. The relative merits of systems and methods of physical training were not discussed, but free play was held to be preferable to grmnastics for physical training. The methods in the former are more spontaneous and thorough, and the most enthusiastic disciple of gymnastics does not wish the gymnasium to take the place of our great games. Discipline, prompt and unquestioning obedience to command, is perhaps the greatest gain derived from class drilling. But the lesson in physical exercise is not the only opportunity for paving attention to the needs of the growing child. If the best results are to be produced, the necessary standing and sitting positions of the pupils throughout the rest of the school routine must not be treated with indifference.

The early age at which children commence education and the length of the school day were both objects of adverse comment. It was pointed out that in primary schools children at three years of age pass the same number of hours in school as those of fourteen years of age : and in secondary schools a child of fourteen has allotted to him the same number of hours of work as the youth of nineteen. Longer intervals of rest and recreation and the abolition of home work for young children were advocated, and it was pointed out that, in the experience of many authorities, the beginning of the day after a night's rest, the commencement of the week after the Saturday and Sunday rest, and the beginning of a term after the rest of the vacation, are the times when the best work is accomplished.

It is at present by no means unusual in many first-grade girls' schools to make the first test which a pupil undergoes a physical one based on a medical inspection. Before a scholarship can be held, physical as well as mental fitness should be required to be shown. It is a waste of public money to allot scholarships to those who are physically unfit to make use of them. But while we may discuss the physical inspection of children as specially referable to the school period of life at which, for convenience, it is conducted, we should keep in mind the bearing of the facts thereby disclosed on the periods of life which precede and follow it. Much educational energy is at present misspent in endeavouring to educate children who are physically unfit, as evidenced in Glasgow by the small proportion of underfed children who reach a reasonable standard of proficiency according to the master's estimate. In this important work of physical inspection the school teacher should be able to cooperate intelligently with the medical man.

Owing to various causes, artificial and economic, thousands of children three years of age are found in English elementary schools. It is a question whether taking the child out of the mother's hands for the greater part of the day, at so tender an age, may not have weakened the maternal instinct. It is certain, on the other hand, that, owing to the high susceptibility to certain infectious diseases amongst such young children, the practice is dangerous; and the conference passed a resolution to the effect that no child should be permitted to begin formal instruction in school classes under the age of six.

The subject of school buildings and equipment is one of great importance. The school premises often need to be improved if they are to illustrate the sanitary precepts which it is necessary to inculcate and if they are to enable the child to pursue its education under the best hygienic environment. The requirements of the Board of Education with reference to the floor space and air space given to each child were subject to some adverse criticism. Surely it may be claimed that as $I_{\vec{b}}$ feet is generally recognised as the healthy minimum floor space per child, ro feet should no longer be officially recognised as sufficient. The school furniture, moreover, generally leaves much to be desired. Observation has shown that the difference in height of the children of the same age may vary from 6 to 11 inches, and this difference in height and growth ought to be provided for in the seats and desks of every class-room if physical deformities are to be prevented. That is to say, the desks and seats should be adjusted to the pupils' bodies, and not the bodies to the desks and seats. Teachers, moreover, must be taught to realise that, though their effective administration may be aided by efficient inspectors, actual daily care in providing fresh air, including cleanliness and teaching the children to use all sanitary appliances with cleanly decency, is a responsibility which cannot be shifted to other people's shoulders. Unfortunately, however, the local authorities themselves nced stimulating and educating. Nor is this to be wondered at when one recalls the fact that the English Board of Education, though responsible for the compulsory attendance at school of some $6,000,000$ children, is bsolutely without expert assistance where problems of health and sanitation are concerned.

The last day of the conference was devoted to discussions upon the training of teachers and scholars in hygiene. No only must the teacher have a knowledge of hygiene, but he must also be made responsible for the supervision of the hygienic environment of the pupil while at school, and he must ever bear in mind the circumstance that he will probably do most to create a sanitary conscience among the rising generation by example and personal influence. The training in the observation of sanitary precepts is a form of moral training, and if the home influences are antagonistic to those of the school the home influences will often prevail. The dirty and neglected child indicates the necessity of attempting to do something to improve the parent. The teaching of hygiene to the scholars must be suitably graduated to the age and capacities of the scholars; whereas from the very commencement of school life the object lessons of a sanitary environment should always be presented to the child, it is not before he at least reaches the age of sevenand several authorities prefer a later age-that he should commence to receive definite instruction in domestic and personal hygiene.

Subsequent to the age of ten or eleven, the scholar may be taught some of the more elementary scientific principles involved in hygiene precept and practice, but in the whole scheme of teaching hygiene it is only from the broadest point of view the simple and essential laws of health that require to be taught. It is almost sufficient to give to the scholar rules regarding health and reasons for them. If the teacher is to have an irtelligent appreciation of the significance of hygienic principles, he must be taught the elements of physiology. The two subjects naturally go hand-in-hand and must be taught together. Their interests mutually reinforce. Physiology gives the basis and hygiene the application.

Reference was made at the conference to the circumstance that it had been repeatedly urged that there is no room for extra subjects such as "hygiene" to be taught at our schools; but surely hygiene, if properly taught, need not contribute to further over-pressure. The subject of hygiene has a great educative value in itself, and there is no subjert which can be so easily co-related to many other branches of knowledge. Hygiene could be introduced as the practical outcome of the whole of the science teaching in the school, and, if the subject is properly taught to the teachers, an enthusiastic and intelligent teacher could prepare his or her own scheme of work and obtain the necessary results without the displacement of a single subject at present being taught. The great requirement for success in whatever may be attempted is an enthusiasm which will stimulate both the teacher and scholar to convert knowledge into conviction and conviction into conduct.

NO. I 842 , VOL. 7 I] 
In connection with the conference there was a trade exhibition of school building and furnishing appliances, which consisted chiefly of school furniture ; and the Board of Education, the Scotch Education Department, the Technical Instruction Department for Ireland, the London County Council, Home Office, \&c., contributed loan exhibits.

A conference upon school hygiene, international in character, is to be held in London in $190^{-}$.

\section{UNIVERSITY AND EDUCATIONAL INTE LLIGENCE.}

Camrridge.-The subject selected for the Adams Prize in 1906 is "The inequalities in the moon's motion due to the direct action of the planets." The successful candidate will receive about $225 l$.

The syndicate appointed to draw up a scheme of instruction and examination in mining engineering has issued a second and amended report to the Senate. It is proposed that a diploma in mining engineering be granted to students who have passed the previous examination and have kept nine terms, and who have attained an honours standard in geolog: and chemistry in part $i$. of the natural sciences tripos and a second class standard in certain of the papers in the special examination in mechanism. The candidates have also to produce a certificate in mechanical drawing. This amended scheme meets the objections which had at one time been raised to the recommendations of the syndicate, and it was warmly welcomed at the discussion in the Senate house a week or two ago.

Mr. William LoriNg, formerly fellow of King's College, Cambridge, and late director of education under the County Council of the West Riding of Yorkshire, has been appointed warden of the Goldsmiths' College, New Cross.

Science states that the Emperor of Germany has directed the German Ambassador to the Inited States to lay before President Roosevelt in official form the suggestion for an exchange of professors between German and American universities which he made to the American Ambassador on New Year's Day.

THE administration of the Board of Education in respect of secondary schools under the board's regulations for secondary schools, as also of charitable trusts and endowments connected therewith, will be conducted in future in the board's offices at Whitehall, and not at South Kensington. All correspondence on these matters should therefore be addressed to the Secretary, Board of Education, Whitehall, London, S.W. This change does not apply to the board's administration under the regulations for evening schools, technical institutions, and schools of art and art classes, which will remain for the present at South Kensington.

Is the Journal of the Royal Statistical Society for December 3I, Mr. L. L. Price contributes a paper on the accounts of the colleges of Oxford, I893-1903, with special reference to their agricultural revenues. An interesting feature of the discussions was the reference to the disastrous results arising from the new statutes drawn up by the last commission, consequent on the fact that the work of the commission was done at a time when agriculture was prosperous, and no sooner had the sittings ceased than agricultural depression came on the country, and the resources of the colleges were seriously hampered.

Tire trustees of the Peabody Education Fund have, we learn from Science, voted to dissolve their trust. An appropriation of $200,000 l$. for the George Peabody School for Teachers in Nashville, Tenn., was made by a unanimous vote, the State and city having together voted an equal sum for the school. This appropriation leaves a fund of approximately $240,000 l$., which will be distributed later among other educational institutions. From the same source we learn that the trustees of Syracuse University are about to construct, with the bequest made to the university by the late Mr. John Lyman, which is said to amount to $40,000 \mathrm{ol}$, a NO. I 842 , vOL. $7 \mathrm{I} 7$ building to be known as the John Lyman Laboratory of Natural History. Mr. Adolph Lewisohn, of New York, has given $1000 l$. for the reconstruction of the chemical laboratories at Dartmouth College.

THE following recent appointments are announced:Dr. Ernst Neumann, associate professor of physics at Marburg; Dr. Emil Wiechert, professor of geophysics at Bonn; Dr. Holleman, of Gröningen, professor of inorganic chemistry at Amsterdam; Dr. Bernhard Dessau, of Bologna professor of physics at Perugia; Dr. C. Russjan, of Cracow, professor of mechanics at Lemberg; Dr. L. Courvoisier, of Heidelberg, observer at the Berlin Observatory Dr. Ferdinand Henrich, associate professor of chemistry at Erlangen; Dr. Boehm, associate professor of mathematics at Heidelberg: Dr. Kueser, professor of mathematics at Breslau; Dr. Th. Vahlen, of Königsberg, associate professor of mathematics at Greifswald; Dr. M Weber, professor of mechanics at the Hanover Technical College; Mr. B. II. Camp and Dr. G. D. Richardson, instructors in mathematics at Wesleyan and Yale Universities respectively.

\section{SOCIETIES AND ACADEMIES.} LONDON.

Royal Society, June I6, I904.- "On the Influence of the Time Factor on the Correlation between the Barometric Heights at Stations more than I000 Miles apart." By F. E. Cave-Browne-Cave, Girton College, Cambridge. Communicated by Prof. Karl Pearson, F.R.S.

The conclusions drawn from the results given in this paper are as follows:-

(I) The correlation between the barometric readings at two stations upwards of 1000 miles apart depends upon the interval between the readings. In the case of Halifax and Wilmington, the correlation is sensible for at least nine days, and it reaches a maximum for an interval of about sixteen hours in summer and twenty-three in winter. For these stations, and also for St. Helena and Cape Town, the observation at the more easterly station should be taken later for maximum correlation.

(2) There is a considerable correlation between the daily rise at Halifax and Wilmington, and this correlation changes with the interval in a manner somewhat analogous to that in which the corrclation between simultaneous heights at two stations approximately on the same meridian depends upon the distance between them.

(3) There are considerable differences between the summer and winter correlations, and these differences are of the same general nature for both pairs of stations considered.

(4) It is possible to predict the barometric height at one station from an earlier height at a second station more than xooo miles away, with a fair degree of accuracy, the mean observed error for forty dates, taken at random, for Halifax and Wilmington, being $0^{\prime \prime} \cdot 15$.

January 19.- "On the Comparative Effects of the Trypanosomata of Gambia Fever and Sleeping Sickness upon Rats." Br H. G. Plimmer. Comnunicated by C. J. Martin, F.R.S.

The organisms used in these experiments were given to the author by Col. Bruce, F.R.S., and they were taken from monkeys which had been inoculated in Africa from cases of the respective diseases; so that when the author's experiments were commenced each organism had been through one monkey, and they were therefore similar as regards conditions.

Rats inoculated with the Trypanosomata from Gambia fever lived about two and a half months; the Trypanosomata were present in the blood from about four weeks after inoculation until death. Post mortem the organisms were present in the blood and in all the organs: the spleen was very much enlarged, and the liver and kidnevs twere congested. The lymphatic glands were enlarged.

Rats inoculated with the Trypanosomata from sleeping sickness lived without any symptoms for a period of from six to nine months, when they became paralysed first in one hind leg and then in the other, and they died in from 